\title{
Syndemic approach in preventing perinatal near miss before first phase of three delay model
}

\begin{abstract}
Perinatal near miss covers the maternal and neonatal morbidity that refers to two targeted group of mother and baby. Maternal and perinatal mortality are two health indicators that showed very wide gaps of achievement by types of country based on income according to MDG achievement in 2015. The risk of a woman in a developing country dying from a maternal-related cause during her lifetime is much higher compared to a woman living in a developed country. Even though pattern of mortality shows declining trend in many countries, the MDG achievement has trigger more efforts to be geared and aligned. Researchers focus in assessing factors and determinant of maternal and perinatal mortality has shifted into severe morbidity cases or near miss cases. Many evaluation of obstetric care management based on the three delay model enable providers to identify points for improvement and has been mushrooming providing evidence based in scientific literature. However, where we need to focus for intervention and what kind of approaches is suitable is hardly seen published for our reference. Promoting wellbeing and ensure health are elements focussed in SDG provides ways in hindering health trajectory like perinatal near miss. However, the conceptualize approach needs to be narrated to the root of the problems. Evaluating evidence based medicine and scientific models help in generating solution on the root cause problem solving. Syndemic approach in designing preventive public health program targeting improving maternal and perinatal health is complex. It must involve pertinent component related to understanding on health seeking behaviour pattern, the monitoring and evaluation program based on log frame matrix analysis and understanding the dynamic of problem origin using three delay models.
\end{abstract}

Keywords: syndemic approach, perinatal, near miss, public health, three delay model
Volume 2 Issue 4 - 2017

\author{
Rosnah Sutan, Areena Yusof \\ Department of Community Health, University Kebangsaan \\ Malaysia Medical Centre, Malaysia
}

\begin{abstract}
Correspondence: Rosnah Sutan, Public Health Physician (Family Health Group), Community Health Department, University Kebangsaan Malaysia Medical Centre, Bandar Tun Razak Cheras 56000, Kuala Lumpur, Malaysia, Tel +60391455896, Fax +603-91456670, Email rosnah_sutan@yahoo.com
\end{abstract}

Received: March 10, 2017| Published: June 12, 2017
Abbreviations: MDG, millennium development goal; SDG, sustainable development goal; PMR, perinatal mortality rate; MMR, maternal mortality rate

\section{Introduction}

Maintain good health should be promoted as an on-going process since intrauterine period. Way to ensure health will be determined by multifactorial aspects has nicely been lay out in social determinant of health framework by World Health Organization (WHO). ${ }^{1}$ Lesson learned from MDG teach us on focusing more effort in ensure health and well-being for all, at every stage of life. ${ }^{2}$ The present write up is based on several studies carried out by authors locally and published. ${ }^{3-5}$ The recent technical handbook by $\mathrm{WHO}^{2}$ has open up ideas in continuity of finding the best solution for the country and implements it using the innov8 approach as described by the WHO. ${ }^{2}$ The innov8 approach ${ }^{2}$ describes 8 steps in analytical process for program management:

a. Step 1: Complete the diagnostic checklist.

b. Step 2: Understand the program theory.

c. Step 3: Identify who is being left out by the program.

d. Step 4: Identify the barriers and facilitating factors that subpopulations experience.

e. Step 5: Identify mechanisms generating health inequities. f. Step 6: Consider intersect oral action and social participation as central elements.

g. Step 7: Produce a redesign proposal to act on the review findings.

h. Step 8: Strengthen monitoring and evaluation.

Synthesis of problems framework to identify the root cause has urge authors to contribute in the present discussion using Syndemic approach that recently has been noted as good public health approach. ${ }^{6}$ In the planning of health intervention to promote healthy mother and healthy baby has highlight important issues in organizing effort to inculcate healthy lifestyles activity using multi agencies approach. A plan pregnancy helps in providing good birth outcome. However, social, financial healthcare system support do play an important role in determine safe motherhood ${ }^{7}$ that can be handled by multiagency joint effort.

Maternal health refers to the health of women during pregnancy, childbirth and the postpartum period. It encompasses the health care dimensions of family planning, preconception, prenatal and postnatal care in order to reduce maternal and perinatal morbidity and mortality. Maternal health is a critical issue in countries that are struggling to increase their population's health, income, and overall well-being. According to the $\mathrm{WHO},{ }^{8}$ " A maternal death is defined as the death of a woman while pregnant or within 42 days of termination of pregnancy, irrespective of the duration and site of the pregnancy, from any cause related to or aggravated by the pregnancy or its 
management but not from accidental or incidental causes". The risk of a woman in a developing country dying from a maternal-related cause during her lifetime is about 23 times higher compared to a woman living in a developed country. ${ }^{9}$ Maternal mortality is a health indicator that shows very wide gaps between rich and poor, urban and rural areas, both between countries and within them.

It is estimated that, every day in 2013 , about 800 women died due to complications of pregnancy and child birth. ${ }^{10}$ Almost all of these deaths occurred in low-resource settings, and the vast majority of these deaths are preventable. The primary causes of death are haemorrhage, hypertension, infections, and indirect causes, mostly due to interaction between pre-existing medical conditions and pregnancy. Most of these deaths can be avoided as the necessary medical interventions exist and are well known. The key obstacle is pregnant women's lack of access to appropriateness care before, during and after childbirth.

Appropriate timing is extremely important to improve medical care in obstetric emergencies. The key element to reduce maternal mortality is by providing timely treatment to obstetric emergencies. Thus, three delay models ${ }^{11}$ was developed two decades ago to evaluate the factors and determinant surrounding access to appropriate emergency obstetric care especially for high risk cases. Three delay mode ${ }^{11}$ describes delay as having three phases which are;

A. Phase I- delay to seek for treatment by the patient or the family.

B. Phase II- delay in reaching an adequate health facility and getting diagnosed.

\section{Phase III- delay in receiving an adequate care or treatment.}

Three delay models ${ }^{11}$ have been used to assess maternal mortality. This model helps in determining where improvements could be made to prevent morbidity and mortality. However, as the maternal mortality has improved tremendously especially in developed country, maternal near miss was used instead. Maternal near miss ${ }^{12}$ case is defined as a woman who nearly died but survived a complication that occurred during pregnancy, childbirth, or within 42days of termination of pregnancy. Maternal near miss constitutes a proxy to maternal death as they survived severe maternal complication. Maternal health will determine the birth outcome. Therefore in this discussion, the word perinatal near miss is used to refer the mother and the baby. Studies using maternal near miss are more accepted nowadays ${ }^{13-15}$ as it is not as rare as maternal death. The FEMHEALTH project ${ }^{16}$ has defined the health care near-miss as negative events or omissions which occurred in the process of care but which did not (necessarily) lead to serious harm. So far till present the perinatal near miss is never been used in the literature a limited number exploring ways to improve it.

\section{Delayed decision to seek care (Phase I)}

Delayed in making decision to seek care was significant risk factor that increases maternal near miss cases and maternal mortality. A study conducted in Morocco ${ }^{17}$ found that the main reasons given by the women for the first delay were lack of parent's authority to go to a facility and fear of the health facility. It was also found that about one-third of them had attempted delivery assisted by a traditional birth attendant. Another study found that more than half of severe maternal morbidity was related to phase I delay. ${ }^{13}$ The first delay is often discussed as a barrier to the healthcare facilities utilization. It is a process depending on socioeconomic and cultural background, logistic and quality of care. ${ }^{11,18}$ There are studies showing that women will only look for treatment when they had life threatening condition but some of them were not able to recognize the conditions. ${ }^{13,19-21}$ In a less developed countries, studies reported that fear of hospitals and lack of financial resourced to pay for transportation made them delaying the decision to go to the hospitals. ${ }^{17}$ Similarly, in rural setting, living conditions and lack of physical access to health facility were among the determinant of maternal morbidity and mortality. ${ }^{19,20}$

However, a study conducted in urban setting in Bolivia where there are several maternity hospitals and located in short distance found that majority of near miss cases arrived in critical condition. ${ }^{18}$ It is quite obvious that the main obstacle to arrive timely is not a physical barrier like transportation but more towards non-physical barriers. Non-physical barriers such as health-seeking behaviour, low education level and lack of contact with the healthcare system are important issues to be addressed that can cause delayed decision in seeking medical care. ${ }^{11,22}$

\section{Delayed arrival at health facility (Phase 2)}

Patients who make timely decision to go to a health facility can still face delay. Phase 2delay explains obstacle after the decision to seek medical care is made and before receiving appropriate care. This happened due to the problem in the accessibility of health services especially in developing countries. Lack of financial resources and lack of a vehicle were among the main factors causing delayed access to emergency obstetric care. Besides that, reaching an appropriate obstetric facility also depends on the distance, travelling time, transportation, cost and road condition between home and the nearest health facility available. ${ }^{23}$ Women who lived in remote area may disadvantage from physical distance to the hospital and face difficulty in access to own transportation or public transport. Public transport is usually not available in rural or remote area. This gap has been improved in many developing countries by implementing outreach program to the marginal group. There are many interventions being implemented to overcome phase 2 delays.

Interventions implemented in developing countries aimed to rectify delay in reaching appropriate health facility for examples telephones, incentive scheme, guideline on referral for health professionals, empowerment of community members to facilitate in referral activities such drive the vehicles and introducing maternity waiting homes for those who stay far away from hospitals. A mother who has no risk can deliver at home assisted by trained birth attendant. Another alternative is to admit high risk mothers to the hospital earlier to anticipate complications. ${ }^{24}$ This strategy is believed to be the key to minimize geographical gap in obstetric care for women in remote rural area.

\section{Delayed provision of adequate care (Phase 3)}

Phase three delay observed that there were many near miss cases had multiple referrals. They made several visits from the periphery/ primary health centre to a district hospital before finally being treated at a tertiary hospital or a university hospital. Difficulties in patients referral and transfer is another barrier identified in achieving adequate emergency obstetric care. ${ }^{25}$ These problems is mostly observed at secondary care level which is usually least developed. World widely, about $15 \%$ of all pregnant mothers is estimated to developed complication that require further treatment at higher level of care. ${ }^{7}$ Some women reported dissatisfaction on the communication between the providers and the patient. Many recent studies found that third 
delay is significantly associated with a higher risk of developing severe maternal morbidity. ${ }^{26-29}$ They found that majority of the patients arrived at the referral health facility in a critical condition or severe complication which indicates barriers to reach the treatment. ${ }^{15,18}$

There are many factors related to health system and quality of care which can affects the maternal and neonatal outcome. ${ }^{19,30}$ A study in Brazil shows lack of emergency care facilities in obstetric unit as a predictor of poorer outcome among patients with eclampsia. ${ }^{13}$ Besides that, absence of clear guidelines, inadequate human resources and insufficient information provided by the health professional to the patients also contribute to worse outcome. ${ }^{31} \mathrm{~A}$ study was conducted in Netherlands to review the standard of care in cases of maternal mortality due to hypertensive diseases in pregnancy found that most cases met the criteria of severe pre-eclampsia as defined in the national guideline. However, they were not treated according to the recommendations of the guideline regarding antihypertensive treatment and the use of magnesium sulphate to prevent eclampsia (substandard care HDP own). ${ }^{32}$ This is due to different preference of medical professionals in choosing treatment based on their experience and availability of resources. Delay in providing quality medical care also can be influenced by the accuracy of medical equipment. An automated blood pressure recording system may underestimate the severity of hypertension in a pregnant mother and leads to inadequate and delayed management ${ }^{32}$ Assessing problems using the three delay models helps in prioritizing area for further improvement and strengthening. The concept of Syndemic approach in maternal and perinatal near miss focussing on the first delay model helps public health program planner to strategies plan for achieving targets in MMR , PMR and near miss cases. Syndemic approach is used to identify persons to be dealt with, to collaborate with, implementing preventive measures timely and monitor regularly for assessment and consolidate recommendation. A good communication and planning within neighbourhood networking parties should be the first target as the problems will be identify early and intervention plan will be specific and tailored to local socio-cultural value and need. A strategic plan monitoring using a single log frame metric framework analysis shared by all persons that should involve as Syndemic approach under agreed program policy will be able to gear future improvement. The social determinant of health (SDH) framework as suggested by $\mathrm{WHO}^{2}$ will be able to help in strategies plan focussing prioritize domains than need to cater in relation to the first stage delay model.

\section{Conclusion}

Three delay models help us in identifying room for improvements in obstetric care to reduce perinatal morbidity and mortality. While it is not realistic to improve all delays in all phases, practising improvement in Phase 1 at community facilities may eventually improve the survival of women of high risk cases. Syndemic approach in planning for the intervention helps in empowering and place accountability of community neighbourhood, agencies nearby facilities within the community towards a concerted effort in fulfilling safe motherhood goal together with healthcare delivery system. Through this approach the pregnant mother will be accepted and motivated to care her own health and pregnancy through accessing antenatal care services. Maternal and neonatal outcome referring to perinatal near miss should be the approach taken at primary or community level as it tackles both mother and baby.

\section{Acknowledgements}

We would like to show our gratitude to the UKM Ethic and research committee who has approve grant research in relation in perinatal health.

\section{Conflict of interest}

Author declares that there is no conflict of interest.

\section{References}

1. United Nations. Progress towards the Sustainable Development Goals Report of the Secretary-General 2016 session, 24 July 2015-27 July 2016, Agenda items 5, 6 and 18 (a). 2016.

2. WHO. Innov8 approach for reviewing national health programmes to leave no one behind: technical handbook. 2016.

3. Sutan R, Berkat S. Does cultural practice affects neonatal survival-a case control study among low birth weight babies in Aceh Province, Indonesia. BMC Pregnancy Childbirth. 2014;14:342.

4. Sutan R, Mohamed N, Tamil AM, et al. A Case Control Study on Maternal Health-Seeking Behavior at Pre-Pregnancy Stage among Mothers with Low Birth Weight Babies. Womens Health Gynecol. 2016;7:46.

5. YK Cheah. Factors Affecting Participation Decision and Amount of Physical Activity among Urban Dwellers in Malaysia. Public Health. 2017;84-84.

6. Merrill Singer. Introduction to Syndemics: A Critical Systems Approach to Public and Community Health. 2009. p. 304.

7. World Health Organization. Mother-Baby Package: Implementing Safe Motherhood in Countries: Practical Guide. Human reproduction programme. 1996:96.

8. World Health Organization. Maternal Mortality in 2005. Estimates Developed by Who, Unicef, Unfpa, and the World Bank. 2010.

9. Wilmoth JR, Mizoguchi N, Oestergaard MZ3, et al. A New Method for Deriving Global Estimates of Maternal Mortality. Stat Politics Policy. 2012;3(2).

10. Sajedinejad S, Majdzadeh R, Vedadhir A, et al. Maternal mortality: a cross-sectional study in global health. Global Health. 2014;11:4.

11. Thaddeus S, Maine D. Too Far to Walk: Maternal Mortality in Context. Soc Sci Med. 1994;38(8):1091-1110.

12. Haddad SM, Cecatti JG, Souza JP, et al. Applying the Maternal near Miss Approach for the Evaluation of Quality of Obstetric Care: A Worked Example from a Multicenter Surveillance Study. Biomed Res Int. 2014;2014:989815.

13. Cecatti JG, Souza JP, Parpinelli MA, et al. Research on Severe Maternal Morbidities and near-Misses in Brazil: What We Have Learned. Reprod Health Matters. 2007;15(30):125-133.

14. Okong P, Byamugisha J, Mirembe F, et al. Audit of Severe Maternal Morbidity in Uganda-Implications for Quality of Obstetric Care. Acta Obstet Gynecol Scand. 2006;85(7):797-804.

15. Souza JP, Cecatti JG, Parpinelli MA, et al. An Emerging "Maternal near-Miss Syndrome": Narratives of Women Who Almost Died During Pregnancy and Childbirth. Birth. 2009;36(2):149-158.

16. Tunçalp Ö, Hindin MJ, Adu-Bonsaffoh K, et al. Assessment of maternal near-miss and quality of care in a hospital-based study in Accra, Ghana. Int J Gynaecol Obstet. 2013;123(1):58-63. 
17. Assarag B, Dujardin B, Delamou A, et al. Determinants of Maternal near-Miss in Morocco: Too Late, Too Far, Too Sloppy? PloS one. 2015;10(1):e0116675.

18. Rööst M, Altamirano VC, Liljestrand J, et al. Priorities in Emergency Obstetric Care in Bolivia--Maternal Mortality and near-Miss Morbidity in Metropolitan La Paz. BJOG. 2009;116(9):1210-1217.

19. Filippi V, Richard F, Lange I, et al. Identifying Barriers from Home to the Appropriate Hospital through near-Miss Audits in Developing Countries. Best Pract Res Clin Obstet Gynaecol. 2009;23(3):389-400.

20. Pembe AB, Urassa DP, Darj E, et al. Qualitative Study on Materna Referrals in Rural Tanzania: Decision Making and Acceptance of Referral Advice. Afr J Reprod Health. 2008;12(2):120-131.

21. Say L. Importance of Accurate Information on Causes of Maternal Deaths for Informing Health Care Programmes. Indian J Med Res. 2010;132:123-124.

22. Rööst M, Johnsdotter S, Liljestrand J, et al. A Qualitative Study of Conceptions and Attitudes Regarding Maternal Mortality among Traditional Birth Attendants in Rural Guatemala. BJOG. 2004;111(12):1372-1377.

23. Combs Thorsen V, Sundby J, Malata A. Piecing Together the Materna Death Puzzle through Narratives: The Three Delays Model Revisited. PloS one. 2012;7(12):e52090.

24. WHO. A Review of Experiences. World Health Organisation, Division of Reproductive Health, Safe Motherhood unit, Maternal and Newborn Health. 1996.

25. Pacagnella RC, Cecatti JG, Parpinelli MA, et al. Delays in Receiving Obstetric Care and Poor Maternal Outcomes: Results from a National Multicentre Cross-Sectional Study. BMC Pregnancy Childbirth 2014; $14: 159$.
26. Lutomski JE, Greene RA, Byrne BM. Severe Maternal Morbidity During Childbirth Hospitalisation: A Comparative Analysis between the Republic of Ireland and Australia. Eur J Obstet Gynecol Reprod Biol. 2012;163(2):148-153.

27. Pacagnella RC, Cecatti JG, Osis MJ, et al. The Role of Delays in Severe Maternal Morbidity and Mortality: Expanding the Conceptual Framework. Repro Health Matters. 2012;20(39):155-163.

28. Shah N, Hossain N, Shoaib R, et al. Socio-Demographic Characteristics and the Three Delays of Maternal Mortality. J Coll Physicians Surg Pak. 2009;19(2):95-98.

29. Zwart JJ, Richters JM, Ory F, et al. Severe Maternal Morbidity During Pregnancy, Delivery and Puerperium in the Netherlands: A Nationwide Population-Based Study of 371,000 Pregnancies. BJOG. 2008;115(7):842-850.

30. González-Block MA, Rouvier M, Becerril V, et al. Mapping of Health System Functions to Strengthen Priority Programs. The Case of Maternal Health in Mexico. BMC Public Health. 2011;11(1):164.

31. Graner S, Klingberg-Allvin M, Phuc HD, et al. Adverse Perinatal and Neonatal Outcomes and Their Determinants in Rural Vietnam 1999. 2005. Paediatr Perinat Epidemiol. 2010;24(6):535-545.

32. Lan PG, Clayton PA, Hyett J, et al. Measuring Blood Pressure in Pregnancy and Postpartum: Assessing the Reliability of Automated Measuring Devices. Hypertension in pregnancy. 2014;33(2):168-176. 